\title{
COMPORTAMENTO IN VITRO DE Chalara paradoxa, AGENTE CAUSAL DA PODRIDÃO-NEGRA DO ABACAXIZEIRO, EM DIFERENTES CONDIÇÕES DE CULTIVO ${ }^{1}$
}

\author{
WILZA CARLA OLIVEIRA DE SOUZA ${ }^{2}$, LUCIANA CORDEIRO DO NASCIMENTO ${ }^{4}$, \\ TARCIANA SILVA DOS SANTOS ${ }^{3}$, JULIANA DE MACÊDO VIDAL ${ }^{3}$, \\ HILDERLANDE FLORÊNCIO DA SILVA ${ }^{3}$
}

RESUMO-Na pós-colheita do abacaxizeiro, a podridão-negra é considerada como um dos principais problemas na comercialização dos frutos. A doença é causada pelo fungo Chalara paradoxa (De Seynes) Sacc.. Apesar da importância deste patógeno para a cultura, são poucas as informações relacionadas ao estudo do mesmo, com base em características fisiológicas in vitro. Assim, o objetivo do trabalho foi avaliar o crescimento micelial, a esporulação e a germinação de C. paradoxa, em diferentes condições de cultivo. A partir de placas contendo colônias puras do isolado de C. paradoxa, foram retirados individualmente discos para inoculação em diferentes meios. A incubação das placas foi feita em três diferentes regimes de luminosidade e em três diferentes temperaturas. Para o crescimento micelial, esporulação e germinação, as melhores condições de cultivo in vitro de C. paradoxa foram os meios aveia (OA) e batata (PDA) em alternância luminosa a $25^{\circ} \mathrm{C}$, os meios batata (PDA) e abacaxi (PJA) no escuro contínuo, na mesma temperatura.

Termos para indexaçaõ: Ananas comosus L., crescimento micelial, esporulação, germinação.

\section{BEHAVIOR IN VITRO OF CHALARA PARADOXA, CAUSAL AGENT OF PINEAPPLE BLACK ROT IN DIFFERENT GROWTH CONDITIONS}

ABSTRACT - In pineapple postharvest, black rot disease is considered as the main problem of fruits trade. The disease is caused by the fungus Chalara paradoxa (De Seynes) Sacc.. Despite the importance of this pathogen to pineapple, there is little information related to it, based on physiological characteristics in vitro. The objective of the study was to evaluate the mycelial growth, sporulation and germination of C. paradoxa in different growing conditions. Mycelial discs were removed from pure cultures and placed for growing on petri plates containing the medias: potato-dextrose-agar (PDA), oat-agar (OA), coconut milk-agar (CMA), and pineapple juice agar (PJA).Incubation of the plates was done at three different light regimes and three different temperatures. For mycelial growth, sporulation and germination the best conditions of in vitro cultivation of $C$. paradoxa were OA and PDA medias in alternating light at $25^{\circ} \mathrm{C}$, the PDA and PJA medias in continuous darkness at the same temperature

Index terms: Ananas comosus L., mycelial growth, sporulation, germination

${ }^{1}$ (Trabalho 192-15). Recebido em: 17-07-2014. Aceito para publicação em: 11-06-2015.

${ }^{2}$ Mestre em Agronomia PPGA (UFPB)- Centro de Ciências Agrárias (CCA) - Campus II. Areia, PB, Brasil. E-mail:wilza-souza@ hotmail.com

${ }^{3}$ Estudante de Graduação em Agronomia, UFPB-PB. E-mail: tarciana.agronomia@gmail.com; ju_agronomia@hotmail.com; hildinhasilva_2009@hotmail.com

${ }^{4}$ Professora D. Sc. CCA - Campus III- Dep.de Fitotecnia. UFPB-PB. E-mail: luciana.cordeiro@cca.ufpb.br 


\section{INTRODUÇÃO}

Na pós-colheita do abacaxizeiro, a podridãonegra é considerada como um dos principais problemas na comercialização dos frutos. A doença é causada pelo fungo Chalara paradoxa (De Seynes) Sacc. (= Thielaviopsis paradoxa (De Seyn.) Hohn., teleomorfo: Ceratocystis paradoxa (Dade) C. Moreau) (INDEX FUNGORUM, 2014; MATOS, 2005).

O cultivo in vitro de $C$. paradoxa é um dos entraves para o desenvolvimento de estudos específicos sobre a característica do microrganismo, pois o conhecimento das condições ideais para o seu cultivo ainda são um quesito a ser observado. Poucos relatos científicos dessa natureza são encontrados na literatura atual remetendo a estudos que possam enriquecer esse banco de informações.

Ao reproduzir fungos in vitro, alguns fatores precisam estar de acordo com as necessidades do fungo, tanto nutricionais quanto ambientais. Dentre os fatores, estão luminosidade e temperatura, importantes para o crescimento micelial e produção de esporos. No entanto, nem sempre as condições que favorecem o crescimento são as mesmas para esporulação. Sabe-se ainda que alguns meios de cultura são mais favoráveis para o crescimento e esporulação de fungos que outros, por apresentarem substâncias nutritivas complexas que são menos exigidas para a produção de hifas vegetativas, porém mais exigidas à produção de esporos (HANADA et al., 2002).

A temperatura exerce influência no crescimento, esporulação e germinação dos fungos por ser um dos principais fatores ambientais que afetam a taxa de crescimento vegetativo e a produção de esporos (WINDER, 1999; TEIXEIRA et al., 2001). Resultados de pesquisas indicam que as mudanças na temperatura podem alterar o estágio e a taxa de desenvolvimento do patógeno, sua agressividade ou virulência e suas relações fisiológicas (GARRET et al., 2006).

A luminosidade, para a maioria dos organismos, é um fator ambiental que regula o desenvolvimento e os processos de metabolismo (BABITHA et al., 2008). O crescimento das várias espécies de fungos parece ser diferentemente influenciado pela luz. No trabalho desenvolvido por Monteiro et al. (2004) com isolados de Verticillium lecanii, a ausência de luminosidade proporcionou a melhor condição para o crescimento, quando comparados com o regime de luz contínua e alternada.

Assim, o objetivo do trabalho foi avaliar o crescimento e a esporulação de C. paradoxa in vitro sob diferentes condições de cultivo.

\section{MATERIAL E MÉTODOS}

O trabalho foi conduzido no Laboratório de Fitopatologia, Centro de Ciências Agrárias - CCA, Universidade Federal da Paraíba - UFPB.

A partir de placas contendo colônias puras do fungo C. paradoxa, foram retirados, individualmente, discos com cinco mm de diâmetro, para inoculação nos meios de cultura de aveia-ágar (OA; $60 \mathrm{~g}$ Aveia em Flocos Quaker ${ }^{\circledR}, 10 \mathrm{~g}$ dextrose, $15 \mathrm{~g}$ Ágar) adaptado de Googing e Lucas (1959); de batatadextrose-ágar (PDA; $200 \mathrm{~g}$ batata, $10 \mathrm{~g}$ dextrose, 15 g Ágar) adaptado de Riker e Riker (1936); de leite de coco (CMA; $200 \mathrm{~mL}$ de leite de coco, $20 \mathrm{~g}$ dextrose $15 \mathrm{~g}$ Ágar) adaptado de Menezese SilvaHanlin (1997); e de abacaxi (PJA; $200 \mathrm{~mL}$ do suco do abacaxi puro, $20 \mathrm{~g}$ dextrose, $15 \mathrm{~g}$ Ágar) adaptado de Romero e Gallegly (1963) para 1.000 mL de água destilada esterilizada (ADE).

$\mathrm{O}$ pH de todos os meios foi ajustado para 5,0 (WISMER, 1961). A incubação das placas $(90 \mathrm{~mm}$ ) contendo o fungo foi feita em três diferentes regimes de luminosidade (claro contínuo, escuro contínuo e alternância luminosa) e três diferentes temperaturas $\left(15, ; 25\right.$ e $\left.35^{\circ} \mathrm{C}\right)$. As placas contendo os discos permaneceram em câmara incubadora B.O.D com controle de temperatura e fotoperíodo.

A avaliação foi realizada diariamente, mediante o uso de paquímetro digital, com mensurações diametralmente opostas, sendo aferida a média, para a determinação do crescimento micelial.

A quantificação do número de esporos produzidos e germinados em cada tratamento foi feita ao final do experimento. Para fins de avaliação, o esporo foi considerado germinado quando o comprimento de seu tubo germinativo foi maior ou igual ao menor diâmetro do esporo (AMORIM et al., 2011).

A suspensão de esporos foi obtida pela adição de $20 \mathrm{~mL}$ de ADE nas placas de Petri e raspagem da colônia com escova de cerdas macias. A filtragem da suspensão deu-se por intermédio de uma camada dupla de gaze estéril, sendo determinados o número de esporos e os esporos germinados $\left(1,0 \times 10^{4} /\right.$ $\mathrm{mL}$ ) em hemacitômetro. $\mathrm{O}$ delineamento estatístico utilizado foi o DIC (Delineamento Inteiramente Casualisado), com cinco repetições (cada repetição composta por cinco placas), em arranjo fatorial 4 x 3 x 3 (quatro meios de cultura (PDA, OA, CMA, PJA), três regimes de luminosidade (luz contínua, escuro contínuo, alternância luminosa-12 horas de claro e 12 
horas de escuro) e três temperaturas $\left(15 ; 25 \mathrm{e} 35^{\circ} \mathrm{C}\right)$.

Os dados obtidos foram submetidos à análise de variância; e as médias, comparadas entre si, pelo teste de Tukey, a 5\% de probabilidade, para testar as hipóteses dos efeitos principais e das interações, utilizando o SOFTWARE SAS versão 9.2 (SAS, 2009).

\section{RESULTADOS E DISCUSSÃO}

As melhores condições de crescimento micelial ocorreram nos meios OA, PDA e PJA, nos três regimes de luminosidade testados e na temperatura de $25^{\circ} \mathrm{C}$ (Tabela 1). Os meios de cultura OA e PDA, ambos ricos em carboidratos, têm função importante no crescimento micelial de fungos fitopatogênicos. Em geral, os fungos fitopatogênicos utilizam para o seu crescimento e desenvolvimento várias fontes nutricionais, entre as quais os açúcares, que são carboidratos mais requeridos pelos fungos, que podem variar desde os mais simples ao mais complexo (ORLANDELLI et al.,2012).

O meio PJA, rico também em carboidratos e amido, contribuiu para os altos valores de crescimento micelial do fungo (Tabela 1), além de a variedade utilizada para a preparação do meio de cultura ser hospedeira de C. paradoxa.

Os valores para crescimento nos meios OA (aveia) 90,0; 90,0 e 88,4 mm, PDA (batata) 89,2; 90,0 e 90,0 mm e PJA (abacaxi) 89,3; 90,0 e $90,0 \mathrm{~mm}$ nas condições de alternância luminosa, escuro contínuo e claro contínuo, respectivamente a $25^{\circ} \mathrm{C}$, demonstraram uma adequação do substrato às exigências fisiológicas do fungo, atingindo os bordos da placa em 4 dias (Tabela 1).

Em CMA, foi observada uma redução no crescimento micelial, em que apenas na temperatura de $25^{\circ} \mathrm{C}$, nos regimes de escuro contínuo, e claro contínuo foi observado um pequeno crescimento de 15,7 e $18,3 \mathrm{~mm}$, respectivamente, e nas demais temperaturas e regimes de luminosidade o fungo não se desenvolveu (Tabela 1). Pode-se sugerir que os constituintes deste meio podem ter interferido no crescimento do fungo por conter excesso de gordura e, em pequena quantidade de carboidratos, não estimulando o pleno crescimento (Tabela 1).

$\mathrm{O}$ fungo $C$. paradoxa é considerado um fungo do tipo amilolítico, ou seja, produz maior quantidade de enzimas extracelulares amilolíticas, degradando amido, substância derivada de carboidratos (ALEXANDRE et al., 2009). Esse fato explica o maior índice de crescimento do fungo em meios contendo maior quantidade de carboidratos.
Nos estudos relacionados ao efeito de temperatura no crescimento da C. paradoxa, Santos et al. (2011) afirmaram ser $25^{\circ} \mathrm{C}$ a temperatura ideal de crescimento, o que corrobora a presente pesquisa. Em isolados de coqueiro (Cocos nucifera L.), Carvalho et al. (2011) concluíram como a exata temperatura ótima para o crescimento micelial da C. paradoxa a de $28,28^{\circ} \mathrm{C}$, e Yadahalli et al. (2007) observaram o desenvolvimento em abundância entre as temperaturas de 25 e $28^{\circ} \mathrm{C}$, aumentando o limite para o desenvolvimento vegetativo do fungo.

Por se tratar de um fungo que se manifesta na vida pós-colheita, e a maioria dos plantios de abacaxizeiro encontrar-se em regiões em que a faixa de temperatura se situa entre 15 e $30^{\circ} \mathrm{C}$, este fungo torna-se um sério problema nesta fase, necessitando de refrigeração para prevenir perdas ocasionadas pela podridão-negra dos frutos (QUYEN et al., 2013).

Os regimes de luminosidade testados não apresentaram diferenças significativas entre si, nos meios OA, PDA e PJA e na temperatura de $25^{\circ} \mathrm{C}$ (Tabela 1).

Na alternância luminosa e no escuro contínuo a $25{ }^{\circ} \mathrm{C}$, os três meios de cultura (OA, PDA e PJA) que obtiveram maior crescimento micelial obtiveram também os melhores índices de esporulação (Tabela 2).

No trabalho desenvolvido por Carvalho et al. (2011), avaliando diferentes condições ambientais no crescimento e na esporulação de $C$. paradoxa, eles observaram como melhor temperatura para esporulação a de $28,99^{\circ} \mathrm{C}$, e o crescimento, a de $28,28^{\circ} \mathrm{C}$, concluindo como estreita a faixa de diferença entre as temperaturas de crescimento de esporulação. Porém, no presente trabalho, algumas condições de cultivo divergiram para o crescimento e para a esporulação da C. paradoxa.

O PJA em alternância luminosa na temperatura de $15^{\circ} \mathrm{C}$ apresentou valores de esporulação de 106,43 x $10^{4}$, embora reduzido crescimento micelial (41,9 $\mathrm{mm})$. Fato semelhante ocorreu a $15{ }^{\circ} \mathrm{C}$ no claro contínuo em meio PDA. Na temperatura a $35^{\circ} \mathrm{C}$ no escuro, apenas o meio PJA apresentou esporulação mais elevada $\left(83,0 \times 10^{4}\right)$ apesar do pequeno crescimento micelial $(22,3 \mathrm{~mm})$ ao comparar com os meios OA e PDA (Tabela 2).

Pesquisas relatam o fato de fatores ambientais e nutricionais influenciarem de forma diferente no crescimento e na esporulação de fungos fitopatogênicos.

Caixeta et al. (2008), ao avaliarem uma interação tripla significativa entre meios de cultura, temperatura e luminosidade, no crescimento micelial e na produção de esporos de isolados de Guignardia 
citricarpa, concluíram que o meio de cultura que melhor estimulou o crescimento micelial foi o meio cenoura a $25{ }^{\circ} \mathrm{C}$ sob o fotoperíodo de 12 horas, e a maior na produção de esporos (conídios) foi verificada em meio PDA a $20^{\circ} \mathrm{C}$, no mesmo fotoperíodo.

Em alternância luminosa a $25{ }^{\circ} \mathrm{C}$, o maior índice de germinação ocorreu nos meios $\mathrm{OA}$ $\left(11,2 \times 10^{4}\right)$ e PDA $\left(10,6 \times 10^{4}\right)$, e no escuro, na mesma temperatura, o meio PDA apresentou índice de germinação de $13,9 \times 10^{4}$ (Tabela 3), com crescimento micelial de $90 \mathrm{~mm}$ (Tabela 1) e maior número de esporos (Tabela 2), comparando-se com os demais meios estudados. No meio PJA em alternância luminosa a $25^{\circ} \mathrm{C}$, em que os resultados para crescimento e esporulação foram de $89,3 \mathrm{~mm}$ (Tabela 1) e 276,0 x $10^{4}$ (Tabela 2), respectivamente, este obteve germinação de 7,6 x $10^{4}$ (Tabela 3), diferenciando-se estatisticamente dos meios PDA e OA nas mesmas condições.
$\mathrm{Na}$ temperatura de $15^{\circ} \mathrm{C}$ em alternância luminosa, os meios OA e PDA apresentaram índices de germinação semelhantes aos obtidos com a temperatura de $25^{\circ} \mathrm{C}$. Na temperatura de $35^{\circ} \mathrm{C}$ no escuro contínuo, o meio PJA apresentou quantidade de esporos germinados alta em comparação à temperatura de $25^{\circ} \mathrm{C}$ no mesmo meio de cultivo e condição luminosa (Tabela 3 ).

Samapundo et al. (2014) explicam a ligação da germinação de esporos em condições adversas ao fato da luta pela propagação da espécie, afirmando que, quando um organismo encontra situação adversa de sobrevivência, este propaga-se para se perpetuar no tempo e espaço. Ao emitir o tubo germinativo, a continuidade de seu desenvolvimento vai depender das condições ambientas e nutricionais impostas ao microrganismo, pois é nesta fase que o mesmo está mais vulnerável aos fatores externos.

TABELA 1- Desdobramento de interação tripla significativa (meio de cultura x regime de luz $x$ temperatura) para Chalara paradoxa para a variável crescimento micelial.

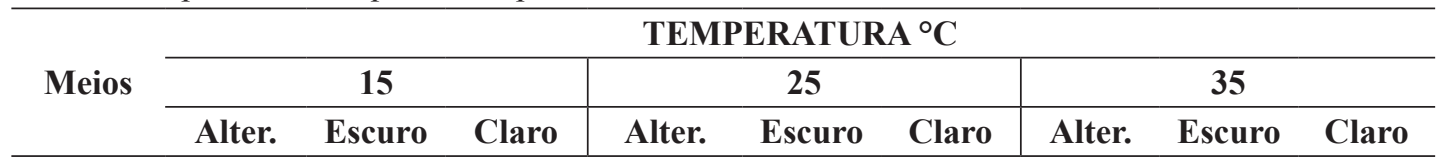

MCA 00,0 Ad $\alpha 00,0$ Ac $\beta \quad 00,0$ Ac $\beta \quad 00,0$ Bb $\alpha$ 15,7 Ab $\alpha$ 18,3 Ab $\alpha 00,0$ Aa $\alpha 00,0$ Ad $\beta$ 00,0 Aa $\beta$

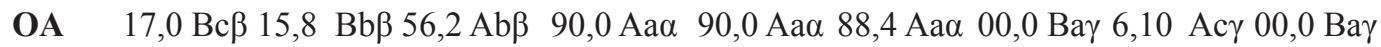

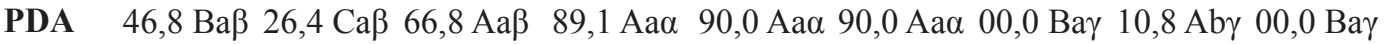

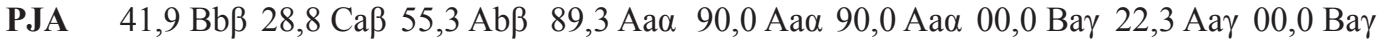

$$
\mathrm{CV}(\%)=11,29
$$

Alter-- Alternância luminosa (12 horas de claro e 12 horas de escuro; Escuro- Escuro contínuo; Claro- Claro contínuo. *Letras minúsculas iguais na coluna não diferem estatisticamente, pelo teste de Tukey, a 5\% de probabilidade, assim como letras maiúsculas iguais na linha em cada temperatura e meio de cultivo e gregas na linha em cada regime de luminosidade. 
TABELA 2- Desdobramento de interação tripla significativa (meio de cultura x regime de luz x temperatura) para Chalara paradoxa para a variável esporulação $\left(1,0 \times 10^{4} / \mathrm{mL}\right)$.

\begin{tabular}{ccc|ccc|ccc}
\hline \multirow{3}{*}{ Meios } & \multicolumn{9}{c}{ TEMPERATURA ${ }^{\circ} \mathrm{C}$} & \multicolumn{3}{c}{35} \\
\cline { 2 - 8 } & Alter. & Escuro & Claro & Alter. & Escuro & Claro & Alter. Escuro & Claro \\
\cline { 2 - 7 }
\end{tabular}

MCA 00,0 Ac $\beta \quad 00,0$ Ab $\beta \quad 00,0$ Ab $\alpha \quad 67,9$ Ab $\alpha \quad 52,6$ Ac $\alpha \quad 00,0 \quad$ Bc $\alpha \quad 00,0$ Aa $\beta \quad 00,0$ Ac $\beta \quad 00,0$ Aa $\alpha$

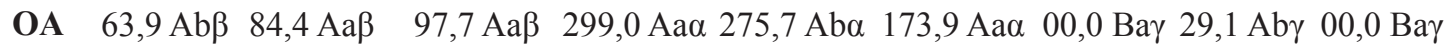

PDA $85,6 \mathrm{Bb} \beta \quad 88,4 \mathrm{Ba} \beta \quad 132,6 \mathrm{Aa} \alpha$ 287,5 $\mathrm{Aa} \alpha$ 318,0 Aa $\alpha$ 128,0 Bb $\alpha$ 00,0 Ba $333,5 \mathrm{Ab} \gamma \quad 00,0 \mathrm{Ba} \beta$

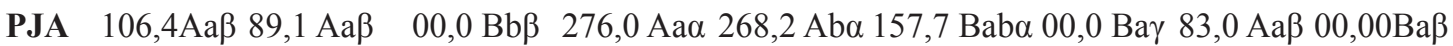

$\mathrm{CV}(\%)=28,44$

Alter-- Alternância luminosa (12 horas de claro e 12 horas de escuro; Escuro- Escuro contínuo; Claro- Claro contínuo.

*Letras minúsculas iguais na coluna não diferem estatisticamente, pelo teste de Tukey, a $5 \%$ de probabilidade, assim como letras maiúsculas iguais na linha em cada temperatura e meio de cultivo e gregas na linha em cada regime de luminosidade.

TABELA 3- Desdobramento de interação tripla significativa (meio de cultura x regime de luz $x$ temperatura) para Chalara paradoxa para a variável germinação $\left(1,0 \times 10^{4} / \mathrm{mL}\right)$.

\begin{tabular}{|c|c|c|c|c|c|c|c|c|c|}
\hline \multirow{3}{*}{ Meios } & \multicolumn{9}{|c|}{ TEMPERATURA $^{\circ} \mathrm{C}$} \\
\hline & \multicolumn{3}{|c|}{15} & \multicolumn{3}{|c|}{25} & \multicolumn{3}{|c|}{35} \\
\hline & Alter. & Escuro & Claro & Alter. & Escuro & Claro & Alter. & Escuro & Claro \\
\hline MCA & $0,0 \mathrm{Ab} \beta$ & 0,0 Ac $\beta$ & $0,0 \mathrm{Ab} \alpha$ & 3,9 Ac $\alpha$ & $3,1 \mathrm{Ab} \alpha$ & $0,0 \mathrm{Bc} \alpha$ & $0,0 \mathrm{Aa} \beta$ & $0,0 \operatorname{Ac} \beta$ & $0,0 \mathrm{Aa} \alpha$ \\
\hline $\mathbf{O A}$ & 8,8 Аa $\alpha$ & $3,0 \mathrm{Ba} \alpha \beta$ & $3,6 \mathrm{Ba} \beta$ & 11,2 Aa $\alpha$ & $3,4 \mathrm{Cb} \alpha$ & 7,9 Ba $\alpha$ & $0,0 \mathrm{a} \beta$ & $0,6 \mathrm{Ab} \beta$ & 0,0 Bay \\
\hline PDA & 9,3 Аa $\alpha$ & $1,9 \mathrm{Cab} \beta$ & 4,6 $\mathrm{Ba} \alpha$ & 10,6 Aa $\alpha$ & $13,9 \mathrm{~A} \mathrm{a} \alpha$ & $3,04 \mathrm{Bb} \alpha$ & $0,0 \mathrm{Ba} \beta$ & $1,2 \mathrm{Ab} \beta$ & $0,0 \mathrm{Ba} \beta$ \\
\hline PJA & $8,8 \mathrm{Aa} \alpha$ & $1,2 \mathrm{Bab} \beta$ & $0,0 \mathrm{Cb} \alpha$ & 7,7 Bba & $10,8 \mathrm{Aa} \alpha$ & 0,0 Cc $\alpha$ & $0,0 \mathrm{Ba} \beta$ & $11,8 \mathrm{Aa} \alpha$ & $0,0 \mathrm{Ba} \alpha$ \\
\hline
\end{tabular}

Alter-- Alternância luminosa (12 horas de claro e 12 horas de escuro; Escuro- Escuro contínuo; Claro-Claro contínuo.

*Letras minúsculas iguais na coluna não diferem estatisticamente, pelo teste de Tukey, a 5\% de probabilidade, assim como letras maiúsculas iguais na linha em cada temperatura e gregas na linha em cada regime de luminosidade. 


\section{CONCLUSÃO}

Para o crescimento micelial, as melhores condições de cultivo in vitro de C. paradoxa foram os meios OA, PDA e PJA a $25^{\circ} \mathrm{C}$ nas três luminosidades estudadas.

Os meios $\mathrm{OV}, \mathrm{PDA}$ e $\mathrm{PJA}$ a $25^{\circ} \mathrm{C}$, em alternância luminosa, e o meio PDA no escuro contínuo, na mesma temperatura, proporcionaram as melhores condições para esporulação.

Para a germinação, os meios OV e PDA em alternância luminosa a $25^{\circ} \mathrm{C}$, os meios PDA e PJA no escuro contínuo na mesma temperatura, o meio PDA em alternância luminosa a $15^{\circ} \mathrm{C}$ e o meio abacaxi, no escuro a $35^{\circ} \mathrm{C}$, proporcionaram os melhores valores de germinação.

\section{REFERÊNCIAS}

ALEXANDRE, E. R.; OLIVEIRA, J.; OLIVEIRA, S. M. A., SANTOS. A. M. G.; LOPES. L. Atividade enzimática de chalara paradoxa, agente etiológico da podridão negra do abacaxi. 2009. Disponível em: http:<//www.eventosufrpe.com.br/jepex2009/ cd/resumos/R0821-1.pdf $>$. Acesso em: 22 jun. 2014.

AMORIM, L.; REZENDE, J. A. M.; BERGAMIN FILHO, A. Manual de fitopatologia: princípios e conceitos. 4. ed. Piracicaba: Ceres, 2011. v.1, 704 p.

BABITHA, S.; CARVALHO, J. C.; SOCCOL, C. R.; PANDEY, A. Effect of light on growth, pigment production and culture morfology of Monascus purpureus in solid-statefermentation. World Journal Microbiology Biotechnology. Oxford, v. 24, p. 2671-2675, 2008.

CAIXETA, P.; CORAZZA, M. J.; OLIVEIRA, R. R.; ZANUTTO, C. A.; NUNES, W. M.C.; VIDA, J. B. Caracterização morfofisiológica e identificação molecular de isolados de Guignardia citricarpa, agente patogênico da mancha preta dos citros. Acta Scientia Agronomica Maringá, v. 30, p. 625-630, 2008. Suplemento.

CARVALHO, R.R.C.; WARWICK, D.R.N.; SOUZA, P.E.; CARVALHO FILHO, J.L.S. Efeito da temperatura no crescimento micelial, produção e germinação de esporos de Thielaviopsis paradoxa isolado de coqueiros em Sergipe. Scientia Plena, Aracaju, v.7, n.9, p.1-5, 2011.
GARRETT, K. A.; DENDY, S. P.; FRANK, E. E.; ROUSE, M. N.; TRAVERS, S. E. Climate change effects on plant disease: Genomes to ecosystems. Annual Review Phytopathology, Palo Alto, v.44, p.489-509, 2006.

GOODING, G. V.; LUCAS, G. B. Factors influencing sporangial formation and zoospore activity in Phytophthora parasitica v. nicotianae. Phytopathology, St Paul, v.49, p. 277- 281, 1959.

HANADA, R. E.; GASPAROTTO, L.; PEREIRA, J. C. R. Esporulação de Mycosphaerella fijiensis em diferentes meios de cultura. Fitopatologia Brasileira, Brasília, v.27, n.2, p.170-173, 2002.

INDEX FUNGORUM. 2014. Disponível em: http:<//www.indexfungorum.org/names/names. asp $>$. Acesso em: 14 jun. 2014.

MATOS, A. P. Manejo integrado da podridão-negra do fruto do abacaxizeiro. Abacaxi em Foco, Cruz das Almas, n.34, 2005. Disponível em: $<$ http://www. cnpmf.embrapa.br $>$. Acesso em: 15 Jun. 2014. (1)

MENEZES, M.; SILVA-HANLIN, D. M. W. Guia prático para fungos fitopatogênicos. Recife: UFRPE, 1997. 106p.

MONTEIRO, A. C.; CLAUDIO, B.; CORREIA, A. C. B.; PEREIRA, G. T. Crescimento e esporulação de isolados de Verticillium lecanii sob diferentes fatores ambientais. Pesquisa Agropecuária Brasileira, Brasília, v.39, n.6, p.561-565, 2004.

ORLANDELLI, R. C.; SPECIAN, V.; FELBER, A. C.; PAMPHILE, J. A. Enzimas de interesse industrial: produção por fungos e aplicações. SaBios: Revista de Saúde e Biologia, Campo Mourão, v.7, n.3, p.97-109, 2012.

QUYEN, D.T.M.; JOOMWONG, A.; RACHTANAPUN, P. Influence of Storage Temperature on Ethanol Content, Microbial Growth and other Properties of Queen Pineapple Fruit. International Journal of Agriculture and Biology, Faisalabad, v.15, n.2, p.207-214, 2013.

RIKER, A. J.; RIKER, R. S. Introduction to research on plant disease. St. Louis: Jonh S. Swift, 1936. 334p. 
ROMERO, S.; GALLEGLY, M. E. Oogonium germination in Phytophthora infestans. Phytopathology, St Paul, v.53, p.899-903, 1963.

SAMAPUNDO, S.; HEYNDRICKX, M.; XHAFERI, R.; BAENST, I.; DEVLIEGHERE, F. The combined effect of pasteurization intensity, water activity, $\mathrm{pH}$ and incubation temperature on the survival and outgrowth of spores of Bacillus cereus and Bacillus pumilus in artificial media and food products. International Journal of Food Microbiology, Amsterdam,v.181, p.10-18, 2014.

SANTOS, J.; REY, M. S.; ROSSETO, E. A.; PIEROBOM, C. R. Comportamento de Ceratocystis sp. "in vitro" sob diferentes temperaturas, meios de cultura e pH. Revista Eletrônica de Educação e Ciência, Recife, v.1, n.1, p.7-17, 2011.

SAS Institute. SAS/STAT. Version 9.2. Cary, 2009.
TEIXEIRA, H.; CHITARRA, L.G.; ARIAS, S.M.S.; MACHADO, J.C. Efeito de diferentes fontes de luz no crescimento e esporulação in vitro de fungos fitopatogênicos. Ciência Agrotécnica, Lavras, v.25, n.6, p.1314-1320, 2001.

WINDER, R. S. The influence of substrate and temperature on the sporulation of Fusarium avenaceum and its virulence on marsh reed grass. Mycological Research, Cambridge, v.103, p.1145115,1999.

WISMER, C. A. Pineapple disease. In: MARTIN, J. P.; ABOUT, E. V.; HUGHES, C. G. (Ed.). Sugarcane disease of the word. Amsterdam: Elsevier, 1961. p. 223-245.

YADAHALLI, K. B.; ADIVER, S.S.; KULKAMI. $\mathrm{S}$. Effect of $\mathrm{pH}$, temperature and relative humidity on development of Ceratocystis paradoxa - a a causal organism of pineapple disease of sugarcane. Kurnataka Journal of Agricultural Sciences, Karnataka, v. 1, n. 20. p. 159-161, 2007. 